\title{
I MPLANTAÇÃO DO CONCEITO DE "POSSE RESPONSÁVEL" NO MUNICíPIO DE PALOTINA/PR - BRASIL
}

\section{Implantation of concept "Responsible Owner" at Palotina/PR - Brazil}

\author{
Erica Cristina B. P. Guirro \\ Kleber Menegon Lemes \\ Suellen Lovato Ribeiro* \\ Marcelo Morato Silva*to \\ Tammy Lyn Labatut Bini i \\ Olicies da Cunha ${ }^{* *+k}$
}

\begin{abstract}
RESUMO
O conceito de posse responsável pode ser definido como a aquisição consciente de um animal de estimação, visando atender a todas as necessidades do animal, garantindo-lhe bem-estar satisfatório. Na tentativa de implantar esse conceito no município de Palotina/PR foram realizadas palestras educacionais e feiras de doação de animais. Cerca de 280 jovens já assistiram às palestras e cerca de 50 animais foram adotados. Com menos de um ano de projeto, tem-se verificado estreitamento da relação entre a população e a comunidade acadêmica, entendimento do que é posse responsável pelos munícipes e ampliação da atividade social por parte dos graduandos.
\end{abstract}

Palavras-chave: Cães; gatos; posse responsável; responsabilidade social.

\begin{abstract}
Concept of responsible owner is conscious acquisition of an animal and considering to caring for all necessities of animal to warrant good well-being. This project objective implant the concept of responsible owner at Palotina/PR and this was done thought educative lectures and donation open-air market. About 280 students and 50 animals were present at lectures and 50 animals were adopted. Until one year of project, have been observed strait relationship between population and academic community, better understanding about responsible owner by population and increase in social activity by academics.
\end{abstract}

Keywords: Cats; dogs; responsible owner; social responsibility.

\section{RESUMEN}

El concepto de pose responsable puede ser definido como la adquisición conciente de un animal de compañía, buscando atender a todas las necesidades de la mascota, garantizándole bien estar. En el intento de implantar ese concepto en el municipio de Palotina, PR - Brasil, fueron realizadas charlas educativas y ferias de donación de animales. Cerca de 280 jóvenes ya participaron de las charlas y alrededor de 50

\footnotetext{
Professora Assistente da UFPR/Palotina, Coordenadora do Projeto de Extensão "Posse Responsável". E-mail: ericaguirro@ufpr.br. Autor para correspondência: UFPR, Rua Pioneiro, 2153, Palotina/PR, CEP 85950-000.

* Acadêmico da UFPR/Palotina, bolsista da PROEC - UFPR

*** Acadêmico da UFPR/Palotina, bolsista da Fundação Araucária (Ação Afirmativa)

wnswa Professor Assistente da UFPR/Palotina, Vice-coordenador do Projeto de Extensão "Posse Responsável"
} 
animales ya fueron adoptados. Fue verificado el estrechamiento de la relación entre la población y la comunidad académica, entendimiento del concepto de pose responsable por parte de los habitantes de la ciudad y aumento de la actividad social por parte de los graduandos.

Palabras-clave: Gatos; perros; pose responsable; responsabilidad social.

\section{Introdução e revisão de literatura}

O tema "posse responsável" é um conceito atual sobre os cuidados que se deve ter com os animais domésticos, especialmente com cães e gatos. Posse responsável pode ser definida como a aquisição consciente de um animal de estimação, visando atender a todas as necessidades do animal, garantindo-lhe bem-estar satisfatório (www.arcabrasil.org.br).

A proliferação descontrolada de cães $e$ gatos é resultado direto do abandono ou maus cuidados vividos por tais animais e, assim, é essencial que haja aplicação de uma política nacional que vise conscientizar a população sobre a necessidade de se cuidar bem dos animais e evitar sua proliferação descontrolada (www.kennelclub.com.br). Segundo o CENSO de 1998, a população estimada do Município de Palotina é de 26.545 habitantes (IBGE, 1998). Como é estimado que a população canina esteja em torno de $10 \%$ da população humana na área urbana, significa que em Palotina existem cerca de 2.500 cães.

No Brasil, o primeiro projeto de lei visando a implantação do conceito de posse responsável foi idealizado pelo Deputado Federal Cunha Bueno, em 1999. Em 2000, tal projeto foi protocolado no Senado e contempla 10 artigos que abrangem cuidados sanitários e garantem o bem-estar animal em todo o território nacional, além de se referir aos cuidados necessários para se evitar acidentes causados por animais errantes (www.nossoscaesegatos.hpg.ig.com.br).

Alguns municípios brasileiros que investiram no esclarecimento e conscientização da importância da posse responsável obtiveram sucesso. A implantação deste conceito tem sido realizada por meio de inúmeras práticas, como registro dos animais de estimação e emprego de diferentes formas de identificação dos animais, como coleiras, chips entre outras, melhoria da saúde e da qualidade de vida dos animais, estimulação da adoção responsável e a manutenção em domicílio dos cães e gatos, prevenção de doenças e estimulação das vacinações, visando a manutenção da saúde e do bem-estar dos animais domésticos e dos seres humanos, melhoria na relação homem-animal, destinação dos animais errantes, utilização dos animais para experimentação, planejamento da natalidade dos animais, facilitando o acesso às cirurgias de esterilização dos cães e gatos, aumento do conhecimento das necessidades e do comportamento dos animais domésticos, entre outros (CARVALHO, s/d; RUIZ, s/d; www.forumnacional.com.br).

Dessa forma, os objetivos fundamentais deste trabalho foram de ordem sanitária e social. O foco sanitário foi o de prestação de serviço de saúde pública, oferecendo informações que contribuam na redução do número de animais soltos nas ruas de Palotina o que, conseqüentemente, pode diminuir os índices de doenças infecto-contagiosas entre os animais e entre o homem e os animais (zoonoses). Os objetivos sociais fundamentaram-se no estreitamento da relação da população com os animais, aumento do vínculo entre a população e a comunidade acadêmica e ampliação o senso de responsabilidade social nos alunos participantes do projeto. 


\section{Material e métodos}

Este projeto iniciou-se no ano de 2007 e continua sendo desenvolvido por meio de duas ações principais: palestras educativas e feiras de doação de animais (Figura 1). Para tais atividades foram selecionados alunos do curso de Medicina Veterinária da UFPR/ Campus Palotina, bolsistas ou voluntários, que são orientados pelos coordenadores do projeto.

As palestras são agendadas, nas escolas públicas e privadas de Palotina, com o auxílio da Secretaria Municipal de Educação. O público alvo envolve jovens de 4 a 15 anos de idade, pois este é o futuro público formador de opinião e, portanto, o ponto chave da implantação do moderno conceito de posse responsável. Dessa forma, estarão sendo formados cidadãos mais conscientes a respeito de sua responsabilidade sobre a presença de animais soltos nas ruas, desprovidos dos cuidados necessários e de medicina veterinária preventiva. Além disso, por ter jovens como público alvo, há maior possibilidade quanto à redução de gastos com vigilância sanitária e recolhimento de animais das ruas.

Diante da diferença quanto ao grau de alfabetização desta faixa etária, criaram-se três modelos de palestras, variando a quantidade de texto e de imagens, mas sempre limitando as apresentações entre 20 a 30 minutos a fim de garantir a atenção do público. Os temas abordados são longevidade dos animais, educação dos filhotes e dos adultos, abrigo, espaço físico necessário, higiene, banhos, alimentação, água, abandono, adoção, cuidados veterinários, vacinação, vermifugação e controle populacional (castração).

As feiras de doação de animais são realizadas durante feiras promovidas pela Prefeitura, por associações de Palotina ou, ainda, em casas agropecuárias que apóiam o projeto. A adoção é precedida do preenchimento de um cadastro com identificação do futuro proprietário que, obrigatoriamente, deve ser maior de 18 anos e, também, no esclarecimento de como se deve cuidar do cão e/ou gato que está sendo adotado e, durante essa explicação, são passadas as mesmas informações contidas nas palestras educativas.

Os animais que são encaminhados à adoção são cães e gatos oriundos da doação ou abandono nas dependências do Campus da UFPR, no município de Palotina/PR. Esses animais são examinados, recebem os cuidados higiênicos adequados e, se a idade permitir, são submetidos à esterilização cirúrgica. Os animais muito jovens que não puderam ser operados são doados, mas o futuro proprietário é informado que pode procurar o Hospital Veterinário quando o animal atingir mais de 6 meses para ser submetido ao procedimento cirúrgico a baixo custo. 
A
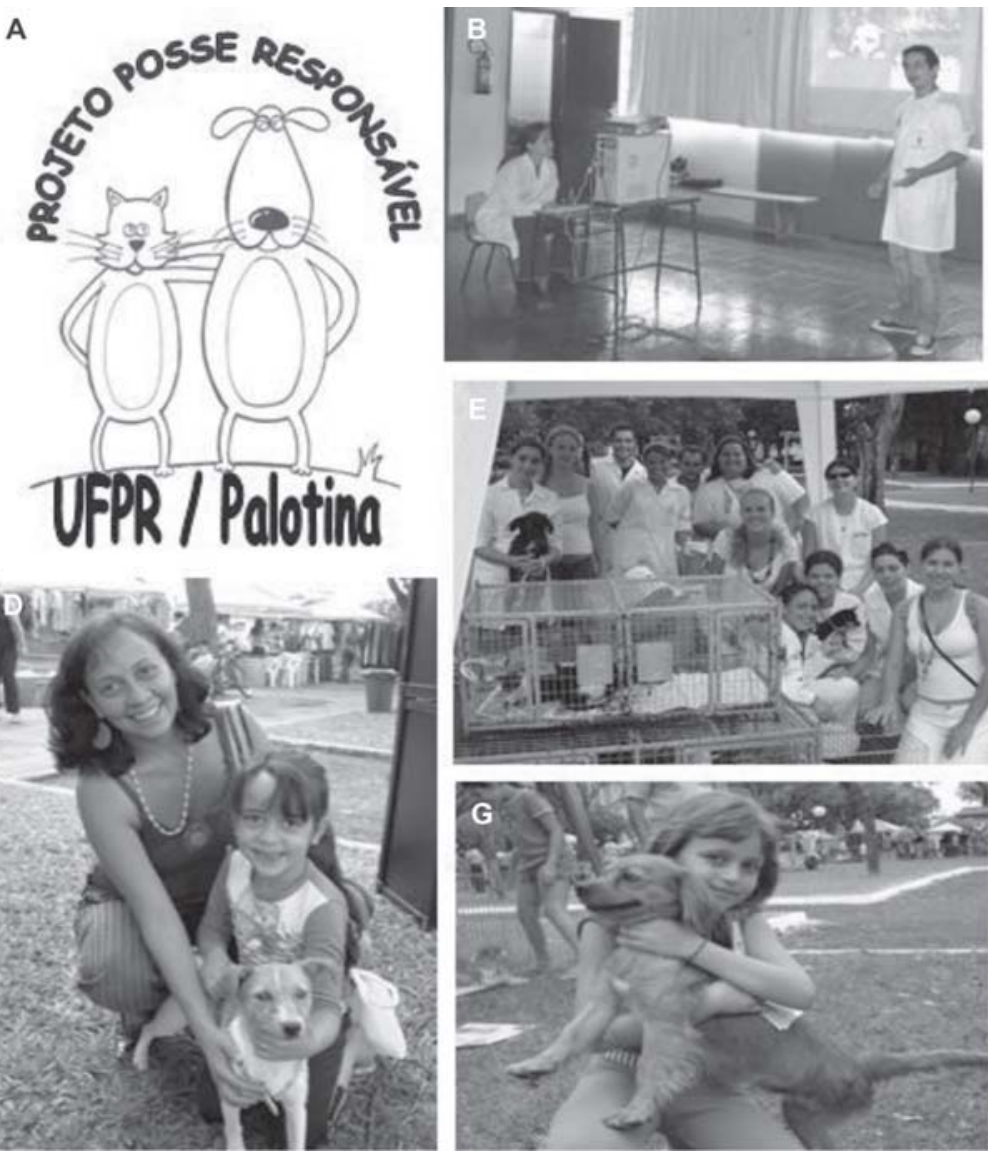
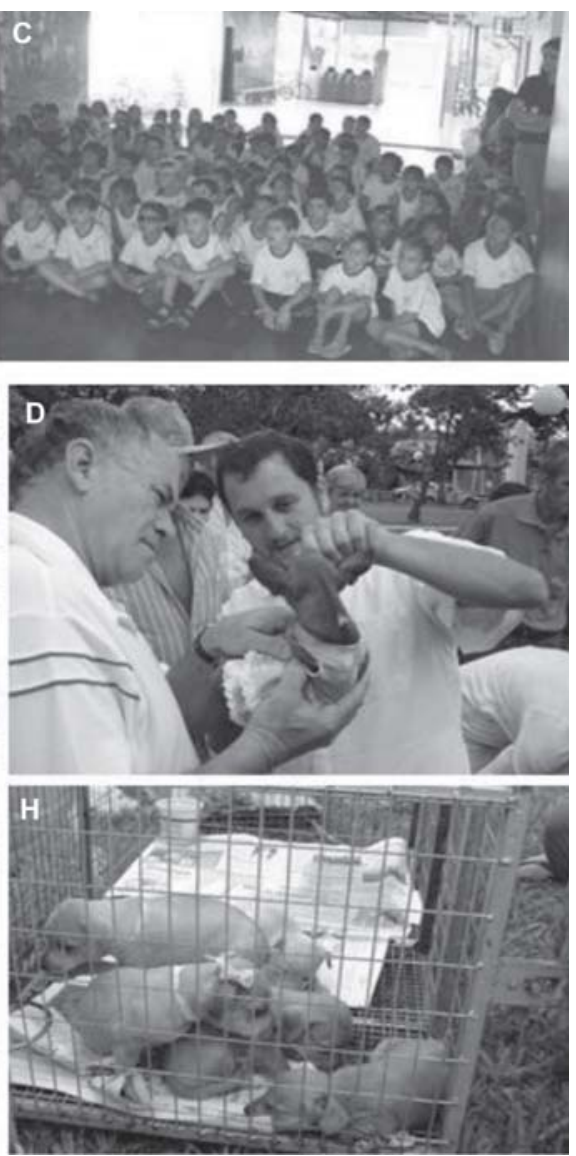

Figura 1 - Execução do projeto de extensão que visa implantar o conceito de posse responsável no município de Palotina/PR. A exibe o logotipo do projeto "Posse Responsável"; B ilustra os acadêmicos bolsistas durante a realização de palestra educativa; $\mathrm{C}$ mostra o público de uma palestra educativa; $\mathrm{D}$ apresenta o momento da adoção de um cão, sempre com a presença de um responsável maior de idade; E mostra os alunos voluntários que participam de feira de doação de cães e gatos; $\mathrm{F}$ exibe um acadêmico explicando como cuidar de um animal que será adotado; $G$ ilustra o interesse de crianças na adoção de animais, inclusive por aqueles que sofreram danos permanentes como a amputação de um membro; $\mathrm{H}$ apresenta um grupo de cães filhotes expostos para a adoção em uma das feiras.

\section{Resultados e discussão}

Como resultados diretos, constata-se que cerca de 280 jovens de 4 a 15 anos já assistiram às palestras e cerca de 50 cães ou gatos foram adotados do modo proposto. Com base nos valores do CENSO de 1998, esses números representariam cerca de $1 \%$ da população humana e $2 \%$ da população de cães, o que passa a ser significativo por ter ocorrido em menos de um ano de criação e execução do projeto.
Indiretamente, é importante salientar que durante a realização das palestras observou-se grande interesse por parte do público e o questionamento dos jovens ao final das apresentações foi notável. Durante as feiras de doação, houve grande aproximação entre a comunidade palotinense e os acadêmicos do curso de Medicina Veterinária, sendo que os munícipes indagavam sobre inúmeros sinais clínicos observados em outros animais e como cuidar de cães e gatos. A Coordenação do projeto decidiu que não seriam realizadas consul- 
tas a outros animais durante as feiras, pois se tratava de ambiente inadequado à prática da Medicina Veterinária. Todavia, orientou-se a população a agendar consultas no Hospital Veterinário da Universidade e observou-se aumento da procura posteriormente às feiras.

Além disso, é importante ressaltar que os acadêmicos que participaram do projeto exibiram enorme satisfação ao final das palestras e das feiras de doação. Os acadêmicos do curso de Medicina Veterinária mostraram extremo interesse pelo contato com os expectadores das palestras e não mediram esforços para responder a todo tipo de questionamento pertinente ao tema. Foram freqüentes os relatos sobre a importância da responsabilidade social vivida pelos acadêmicos que se sensibilizaram ao praticar a profissão que escolheram e poder estreitar a relação com futuros proprietários de animais abandonados. Foi evidente a motivação para a próxima atividade proposta, fosse palestra ou feira.

Notou-se, também, que este projeto recebeu atenção da comunidade, que atualmente vem até o Hospital Veterinário da UFPR/

\section{REFERÊNCIAS}

CARVALHO, V. F. A posse responsável dos animais é um compromisso com a vida. Disponível em $<$ www.webartigos.com/articles > . Acesso em 09/01/2007.

Encontro Proteção Ambiental: O Novo Papel do Centro de Controle de Zoonoses. Disponível em <http:// $\mathrm{w} w \mathrm{w}$. f o r u m n a c i o n a l. c o m . b r/ manifesto s bernardo do campo 2003. pdf $>$. Acesso em $14 / 01 / 2007$.
Campus Palotina em busca de animais para adoção. A imprensa local escrita e falada também procurou a Coordenação do projeto a fim de apoiar sua divulgação.

\section{Conclusões}

Diante do exposto, nota-se que o conceito de posse responsável já tem significado mais claro à população palotinense, que gradualmente tem se mostrado mais atenciosa quanto aos cuidados necessários à criação de animais de estimação e à necessidade de se reduzir o risco de contágio de doenças transmitidas por esses animais. Ademais, é salutar a geração de acadêmicos de Medicina Veterinária mais preocupada com seu papel na sociedade, não apenas no que tange ao trabalho técnico, mas também ao social e voluntariado. Assim, pretende-se continuar com o projeto de extensão "Posse Responsável" a fim de aumentar a inclusão deste conceito na comunidade.

RUIZ, D. MP intervém em causa animal. Disponível em $<$ http://www.tribunaanimal.com>. Acesso em 11/101/ 2007.

Disponível em <www.nossoscaesegatos.hpg.ig.com.br $>$. Acesso em 09/01/2007.

Disponível em <www.kennelclub.com.br> . Acesso em 12/ 01/2007.

Disponível em <www.arcabrasil.org.br>. Acesso em 09/ 01/2007.
Texto recebido em 12 fev. 2008. Texto aprovado em 26 mar. 2008. 